\title{
El Archivo Cultural del Cañar: La creación de un archivo para la comunidad
}

Building a Community Archive: Archivo Cultural de Cañar

\author{
JUDY BLANKENSHIPa , NATALIE BAUR ${ }^{\mathrm{b}}$ \\ a Judy Blankenship, Coordinadora, Archivo Cultural de Cañar, Cañar-Ecuador, \\ 2020 SE Ash Street, Portland, Oregon, 97214, judyblanken@gmail.com \\ ${ }^{b}$ Consultora del proyecto
}

\begin{abstract}
El Archivo Cultural de Cañar es el producto de dos décadas de trabajo documentando las comunidades indígenas que habitan en las montañas en el sur de Ecuador. La primera vez que visité el pueblo de Cañar fue durante los inicios de la década de los noventa. Me encontraba trabajando como voluntaria en un trabajo investigativo con el objetivo de adiestrar a dos hombres cañari, en destrezas en fotografía e historia oral.

Veinte años después, mis lazos con Ecuador se han estrechado más a fondo. Durante el transcurso de estos años he tenido la oportunidad de viajar a Ecuador en múltiples ocasiones para dar clases e instalar exhibiciones. También he escrito dos libros, recibido tres becas Fulbright y construido mi "hogar en las nubes". Actualmente junto a mi esposo compartimos la experiencia de vivir seis meses del año en Cañar y seis meses en la ciudad de Portland, Oregon.
\end{abstract}

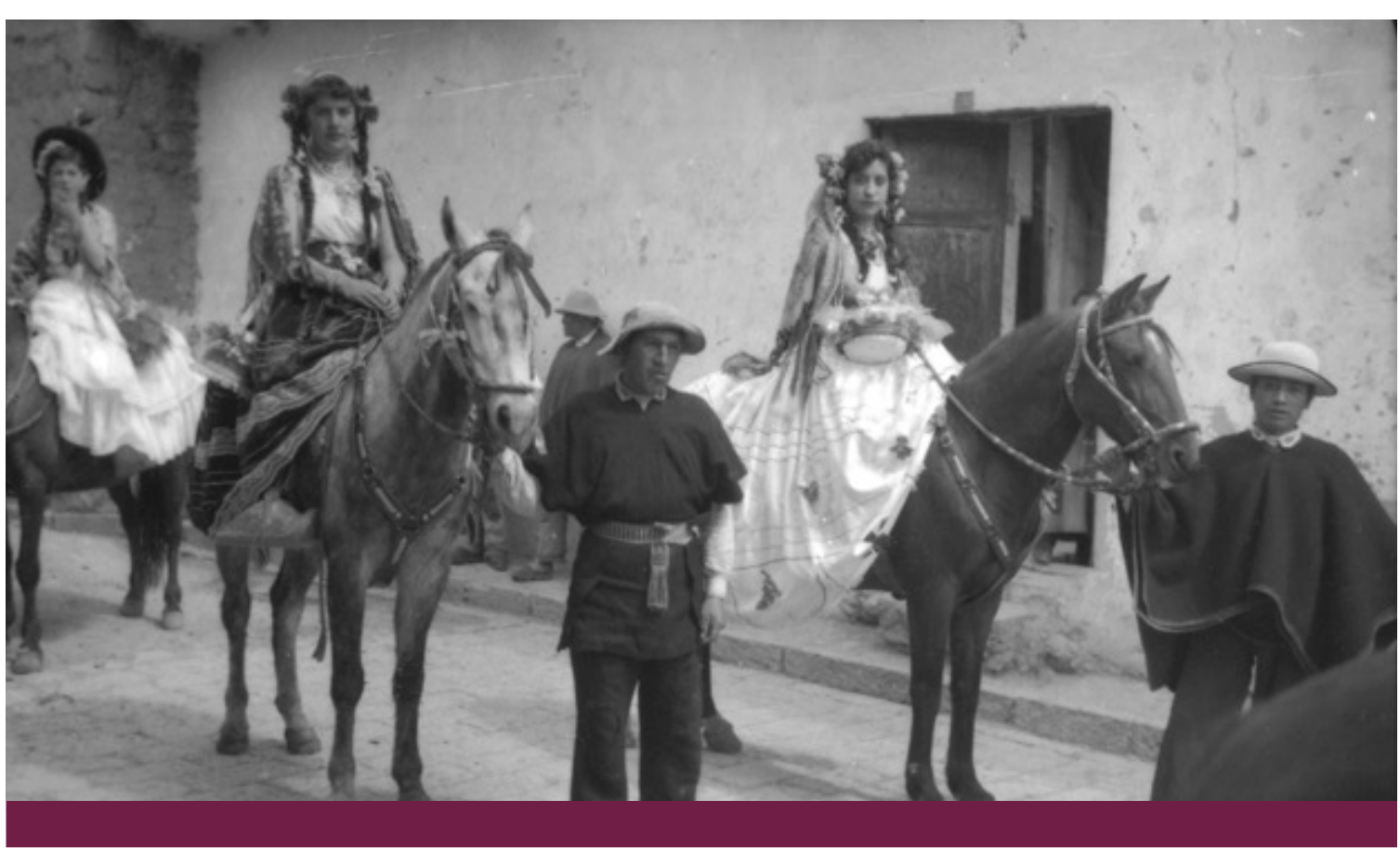

Foto 1. Rigoberto Navas, Cañar (date unknown) 


\section{UN REGISTRO DE LA CULTURA CAÑARI}

Cuando empecé a documentar la cultura del pueblo indígena de Cañar hace cinco años, jamás imaginé que mi idea original se iba a prolongar por tanto tiempo. A petición de la familia de Rigoberto Navas, un fotógrafo del pueblo ya fallecido, respondí a la invitación de visitar su estudio fotográfico para ver una colección antigua de vistas fijas (placas de vidrio) y negativos de película. De vuelta en el cuarto oscuro de mi estudio fotográfico en Cañar, procedí a imprimir una serie de negativos, y de pronto me di cuenta de que había rescatado una pieza invaluable de documentación visual de la vida urbana y campestre a mediados del siglo veinte. De ahí surgió la idea de crear un archivo digital de Cañar, un pequeño pueblo en el sur de los Andes del Ecuador.

Desde entonces, he continuado revelando y escaneando la colección de fotografías de Rigoberto Navas. También me he dado a la tarea de buscar otras colecciones históricas que contengan fotografías, documentos y grabaciones relacionadas al pueblo de Cañar, con énfasis en el periodo final de las haciendas y el inicio de la reforma agraria en Ecuador (1964-1974). A través del internet un grupo de ex-voluntarios del Cuerpo de Paz que habían trabajado en Cañar a finales de los años sesenta, me localizaron y donaron más de 150 diapositivas a color, documentos, libretas de campo, e historias orales a la colección. Estos jóvenes habían llegado al sur de Ecuador con el propósito de ayudar a crear cooperativas agrícolas justo en el momento en que la ley de reforma agraria se puso en marcha. Sus archivos destacan una pieza "perdida" de historia cultural y social de un momento particularmente conflictivo.

Tiempo después me puse en contacto con dos antropólogos daneses que habían hecho una investigación a fondo en el pueblo cañari de El Juncal, a principios de los años setenta. Ellos acordaron escanear y enviar cerca de 1000 imágenes junto con artículos y libros sobre la cultura cañari. Estas imágenes provenientes de otras fuentes son extremadamente valiosas porque, aunque la gente en Cañar utilizaba los servicios de fotógrafos profesionales para dejar constancia de sus vidas privadas y públicas, las comunidades indígenas no gozaban de la misma oportunidad de crear un récord visual de su vida cotidiana y de su cultura.

\section{CREANDO ACCESO A LOS ARCHIVOS}

Trabajar con la comunidad indígena para crear una colaboración mutua dentro de los archivos ha sido una tarea ardua, pero a la vez una parte muy emocionante de este proyecto. Los ancianos se sienten entusiasmados de ver imágenes de su pasado, particularmente de paisajes montañosos, plantaciones y de los festivales de la cosecha,

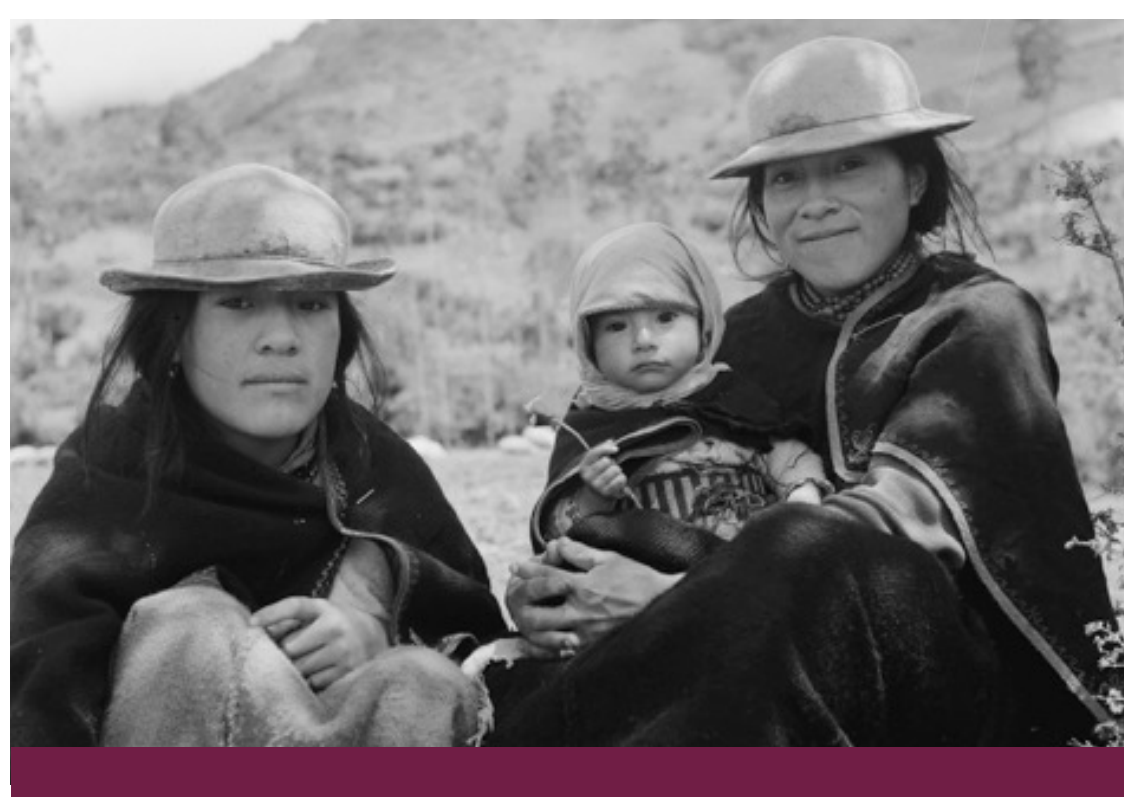

Foto 2. Niels Fock/Eva Krener, Juncal, 1973-4

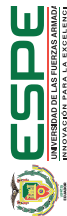




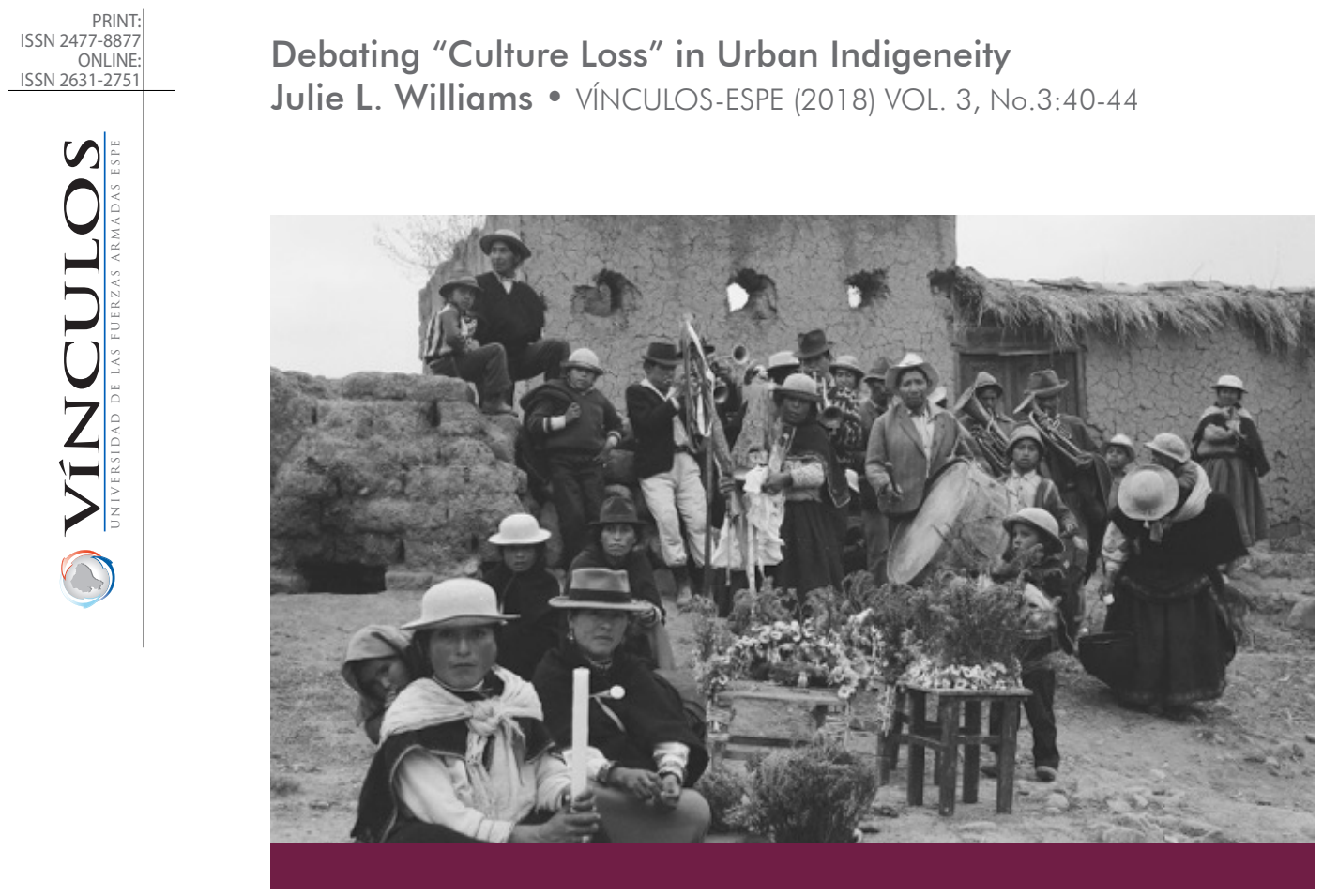

Foto 3. Niels Fock/Eva Krener, Juncal, 1973-4

los cuales son importantes para la sobrevivencia del mundo agrícola, pero al mismo tiempo se han dado cuenta de que esas fotografías podrían ser compartidas con el resto del mundo. Entre los ancianos casi ninguno tiene computadora en su casa o acceso a Internet (aunque casi todos tienen teléfonos móviles).

Así fue como me dirigí a maestros cañari en el Instituto Quilloac, una escuela bilingüe de quechua y español, donde organizamos un comité editorial y un convenio para colaborar juntos en la creación de los archivos. Este ha sido un proceso lento, y creo que tomará un año más o menos antes de que los ancianos de la comunidad y otras partes interesadas puedan ver las colecciones y otorgar permiso para acceso público. Mientras tanto, muestro y comparto las imágenes escaneadas mediante presentaciones y exposiciones, en discos compactos y en versión impresa, con el propósito de recopilar información sobre las mismas.

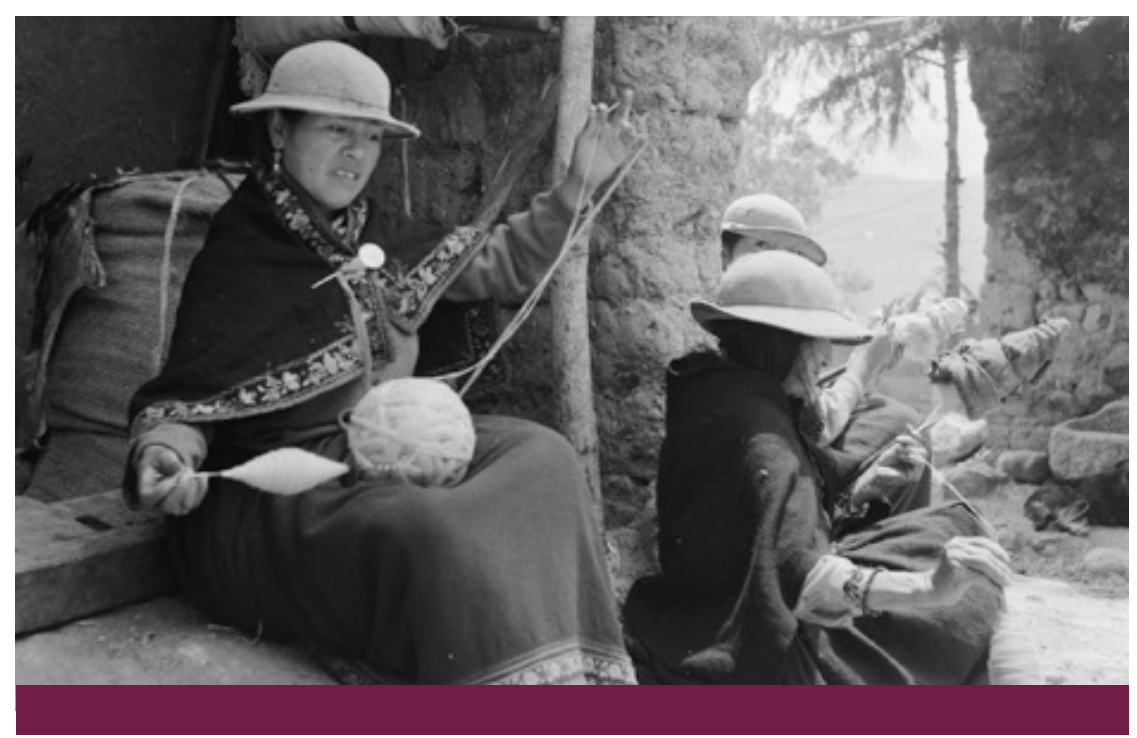

Foto 4. Niels Fock/Eva Krener, Juncal, 1973-4

El año pasado comprendí que tenía que parar de recolectar materiales, y redirigir la dirección del proyecto para enfocarme en el proceso de descripción y preservación de los mismos. Usando una forma simple basada en el esquema de metadatos Dublin Core, creé unas carpetas de la colección las cuales contienen imágenes escaneadas del archivo de Cañar. Estas carpetas las llevaba conmigo en visitas a casas de la comunidad, y a veces las exhibía en eventos públicos para que la gente pudiera revisarlas y agregar información básica como nombres, fechas, nombres de eventos y comentarios.

Al mismo tiempo empecé a explorar programas de código abierto para sistemas de gestión de contenido. Me impresionó lo que había hecho Mukurtu con pueblos originarios del noroeste de los Estados Unidos. Esta plataforma avanzada me pareció una buena opción para el Archivo Cultural del Cañar, porque presenta un modelo sostenible para el manejo ético de materiales del patrimonio cultural. 
Una función interactiva permite a los miembros de la comunidad tener acceso al sistema como administradores o como miembros. Un problema, sin embargo, es el idioma; en tanto que el sistema interno de la plataforma está en inglés, el portal para los usuarios tiene que estar en español. A pesar de ello, empecé a añadir contenido y crear récords de metadatos..

\section{DESARROLLO DE UNA ESTRUCTURA SOSTENIBLE PARA EL ARCHIVO}

En el 2015 Natalie Baur comenzó a trabajar conmigo como consultora del proyecto para crear un sistema sustentable de preservación digital a largo plazo y, para generar capacidad local para el mantenimiento y acceso a las colecciones. Inmediatamente quedó claro que el manejo administrativo transitorio de este proyecto excepcional de archivos de la comunidad - el cual no contaba con financiamiento nacional o internacional - iba a enfrentar dificultades significativas para establecer el manejo de sus recursos digitales, para dar acceso ético y equitativo a las colecciones digitales, y para formar a profesionales locales que puedan llevar a cabo este trabajo. Para ayudar a solucionar estas limitaciones, el grupo de los Itinerant Archivists organizó su primer viaje educativo a Ecuador en septiembre de 2015, para trabajar con archivistas y bibliotecarios ecuatorianos, y dirigentes locales de la comunidad de Cañar.

Cuando Natalie visitó Cañar en junio del 2016, ella se dió cuenta que los estándares tradicionales de archivo y preservación digital, así como la ética alrededor de esos estándares, eran irrelevantes o inadecuados para la tarea en cuestión. Las complicaciones en torno a los derechos, privacidad, acceso y la administración técnica son significativamente más amplias debido a que el proyecto es de base comunitaria y con un enfoque de manejo administrativo transitorio.
Tambien dificulta las decisiones de gestión el hecho de que no cuenta con apoyo de ninguna institución formal (i.e. Universidad, Colecciones especializadas, agencia de gobierno ú organismos sin fines de lucro). Nosotros estamos solo comenzando a trabajar la cuestión de cómo hacer de este proyecto algo sustentable técnica y éticamente. No podemos aplicar estándares formales de archivo sin adaptarlos y modificarlos para que los materiales sean asequibles y preservados mientras sirven a las necesidades e intereses de la comunidad. Gracias a la ayuda de Natalie tradujimos al español el cartel gráfico de "Niveles de Preservación de la Alianza Nacional de Administración Digital (NDSA): una explicación y uso." Nosotros elegimos el modelo de NDSA porque es directo, adaptable y repetitivo. Luego trabajamos en documentar el avalúo y acceso de cada colección, tomar nota del origen de los materiales, el contexto histórico y comunitario en el cual los materiales fueron creados, y las implicaciones que los materiales pueden tener en el acceso y propiedad. Finalmente, nosotros compartimos los estándares traducidos de NDSA y las adaptaciones de las prácticas de preservación digital en una sesión para la comunidad local y con los empleados de archivos y museos.

\section{REDEFINICIÓN DE PROCESOS ARCHIVÍSTICOS}

Como un ejercicio didáctico, el Archivo Cultural de Cañar propone desafiar la idea de que los estándares y prácticas establecidas - creadas siguiendo tendencias profesionales e institucionales - constituyen una base fundamental de la archivística. Por otro lado, aunque nuestro deber nos sugiere ser guiados por los estándares y la capacitación técnica y literal establecidos, por otra parte debemos plantearnos como los mismos pudieran ser o no ser mecanismos apropiados para el trabajo comunitario. Empleada ampliamente y actualmente adoptada por una gran mayoría de archivistas que trabajan con comunidades y proyectos de documentación, esta propuesta está creando una 
visión diferente y un conjunto de instrumentos para documentalistas comunitarios y archivistas.

\section{DESCRIPCIÓN DE FOTOGRAFÍAS}

El trabajo fotográfico de Roberto Navas (1911-2001) captura momentos únicos de la cultura y estilo de vida del pueblo de Cañar. Desde retratos de bodas, estampas de la vida campesina y la vida en las haciendas, todas estas imágenes forman parte del legado fotográfico de Navas.

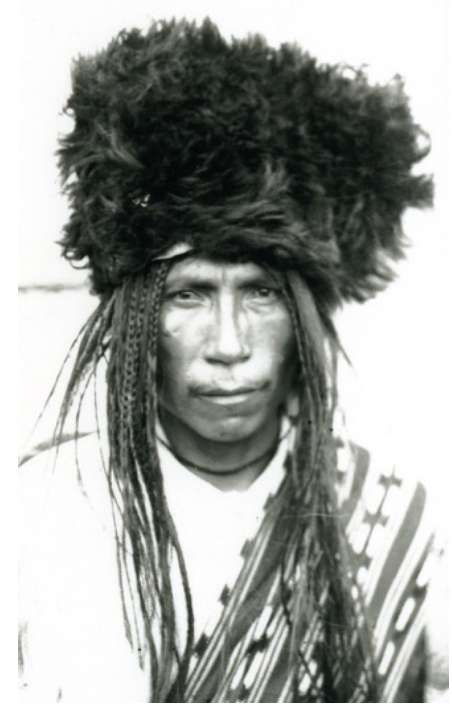

\section{FOFO CREDTIS OF JUNCAL} PHOTOS

Niels Fock/Eva Krener, Juncal, 1973-4.

\section{About the COVER PHOTO}

On Ceremony. A ritual dancer of Cañar Province, Ecuador, circa 1940s, wearing a wig with long thin braids and headdress, part of a costume still used today by the few remaining dancers in the region of Zhud/Suscal. The ikat handwoven shawl on his shoulder is likely from the neighboring province of Azuay, and would be used only on ritual occasions. A traditional everyday garment for a Cañari man is a red ikat 2001), whose extensive photographic collection was the impetus to create a digital community archives of Cañar.

Photo courtesy of the Archivo Cultural de Cañar.

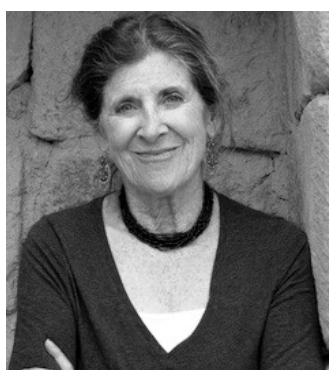

\section{JUDY BLANKENSHIP}

Judy Blankenship, fotógrafa, escritora y editora, vivió en Canadá y América Central antes de establecerse en Portland, Oregón. Desde 2005 su esposo y ella viven seis meses cada año en Cañar, Ecuador, donde sigue documentando la cultura Cañari y ahora está en el proceso de establecer con la comunidades Cañaris un archivo digital, el Archivo Cultural de Cañar.

Los libros sobre su vida en Ecuador incluyen Cañar: Un año en las tierras altas de Ecuador (2005) y Nuestra casa en las nubes: Construyendo una segunda vida en los Andes de Ecuador (2013), ambos publicados por Universidad de Texas Editorial.

Entres sus premios de fotografía, ella ha tenido tres becas Fulbright para sus trabajos de fotografía en Cañar (2000, 2005, 2015-16) y un premio de la Organización de los Estados Americanos (2001).

El Archivo Cultural de Cañar está ahora incluido en una proyecto de tres años de la Fundación Mellon a AILLA, Archivo de Idiomas Indígenas de América Latina en la Universidad de Texas, Austin. 